\title{
Preparation and Electrochemical Study of Ag Nanoparticles Decorated on Gallium Arsenide as Photocatalyst for Methyl Orange Degradation Under Visible Light
}

\author{
Yuan Xu ${ }^{1,2}$, Yun-Sheng Qian ${ }^{1, *}$, Jian-Liang Qiao $^{2}$, Da-Yong Huang ${ }^{2}$, Shao-Bo Cui ${ }^{2}$ \\ ${ }^{1}$ School of Electronic and Optical Engineering, Nanjing University of Science \& Technology, \\ Nanjing, 210094, China \\ ${ }^{2}$ School of Information Engineering, Nanyang Institute of Technology, Nanyang, 473004, China \\ *E-mail: qian_science@sina.com
}

Received: 4 October 2021 / Accepted: 2 November 2021 / Published: 5 January 2022

\begin{abstract}
The purpose of this research was to investigate the electrochemical growth of $\mathrm{Ag}$ nanoparticles on a gallium arsenide (GaAs) electrode and their use as photocatalysts for the degradation of methyl orange (MO) dyes under UV and visible irradiation. SEM and XRD were used to study the morphology and structure of the produced electrodes, revealing that Ag NPs in fcc structures were electrodeposited uniformly on the GaAs electrode surface. According to the optical studies, the optical band-gap values for nanostructured GaAs and Ag NPs/GaAs films were $2.23 \mathrm{eV}$ and $2.16 \mathrm{eV}$, respectively. According to EIS analysis, the Ag NPs/GaAs film had a decreased photo-excited carrier recombination rate due to the effective separation of photo-induced electron-hole pairs. MO photodegradation experiments demonstrate that under UV and visible radiation, complete elimination of MO takes 46 and 40 minutes, respectively. As a result of lowering optical band-gaps, photocatalytic activity on Ag NPs/GaAs photocatalyst was significantly enhanced under visible light.
\end{abstract}

Keywords: Ag NPs/gallium arsenide; Photodegradation; Electrodeposition method; Methyl orange

\section{FULL TEXT}

(C) 2022 The Authors. Published by ESG (www.electrochemsci.org). This article is an open access article distributed under the terms and conditions of the Creative Commons Attribution license (http://creativecommons.org/licenses/by/4.0/). 